\title{
Pyogenic granuloma of the scrotum after treatment of a condyloma with tricholoroacetic acid
}

\author{
Aida Oulehri', Zakia Douhi', Hanane Baybay', Sara Elloudi', Fatima Zahra Mernissi', \\ Imane Gouzi ${ }^{2}$, Layla Tahiri ${ }^{2,3}$, Hind El Fatemi ${ }^{2,3}$
} ${ }^{1}$ Department of Dermatology, University Hospital Hassan II, Fez, Morocco, ${ }^{2}$ Departement of Pathological Anatomy,
University Hospital Hassan II, Fez, Morocco, ${ }^{3}$ Biomedical and Translational Research Laboratory, Faculty of Medicine and
Pharmacy, Sidi Mohamed Ben Abdellah University, Fez, Morocco

Corresponding author: Aida Oulehri, MD, E-mail: aidaoulehri@gmail.com

\begin{abstract}
Pyogenic granuloma (PG) - also known as lobular capillary hemangioma - is a benign vascular tumour that occurs on the skin and mucous membranes. Genital warts—also known as condylomata acuminata-are raised lesions that develop on the skin and mucous membranes after infection with some types of human papillomavirus (HPV). Trichloroacetic acid is very often used, given the availability of the product and its low price. We report an original case of pyogenic granuloma, by its etiology and location. A 33-year-old patient developed a pyogenic granuloma on the scrotum following treatment of a condyloma with trichloroacetic acid. To the best of our knowledge, it's the first case of PG secondary to the application of trichloroacetic acid for the treatment of a scrotal condyloma published in the literature.
\end{abstract}

Key words: Pyogenic granuloma; Scrotum; Condyloma; Tricholoroacetic acid

\section{INTRODUCTION}

Pyogenic granuloma can arise spontaneously, in sites of injury, or within capillary malformations [1]. Anogenital warts (AGW) are epidermal growth lesions, caused by the different genotypes of human papillomavirus (HPV), which occur in the anogenital areas of males and females $[2,3]$. They are a cosmetic nuisance and may cause substantial psychosocial issues for patients, as well as creating an economic burden on healthcare systems. The emotional and psychological issues associated with a diagnosis of AGW can include shame, embarrassment, anger, depression and guilt. [4]. Many treatments are available to treat AGWs. The majority of the treatment modalities for the condition may also cause physical problems such as pain, itching, burning and irritation [5]. We report the case of a scrotal pyogenic granuloma, complicating the application of trichloroacetic acid.

\section{CASE REPORT}

A 33-year-old male, followed for 3 months for ano-genital condylomas treated with $90 \%$ trichloroacetic acid at one session per 15 days, without any other medical history. The patient reports the appearance, following TCA attachment for a scrotal condyloma, of a reddish bleeding lesion that has progressively increased in size over the past 2 months. A physical examination revealed a well-limited lobulated, reddish exophytic vascular nodule, easily bleeding and measuring four centimeters, on the posterior surface of the scrotum (Fig. 1). On dermoscopy, we noticed the presence of multiple reddish homogeneous area also named a vascular lagoons separated by white rail lines corresponding to fibrous septas (Fig. 2a). At higher magnification, we found a rich, linear, irregular and tortuous vascularization in these lagoons (Fig. 2b). We performed an excision of the lesion by electrocoagulation. Histopathological

\footnotetext{
How to cite this article: Oulehri A, Douhi Z, Baybay H, Elloudi S, Mernissi FZ, Gouzi I, Tahiri L, EL Fatemi H. Pyogenic granuloma of the scrotum after treatment of a condyloma with tricholoroacetic acid. Our Dermatol Online. 2021;12(e):e34.

Submission: 14.12.2020; Acceptance: 11.03.2021

DOI: 10.7241 /ourd.2021e.34
} 


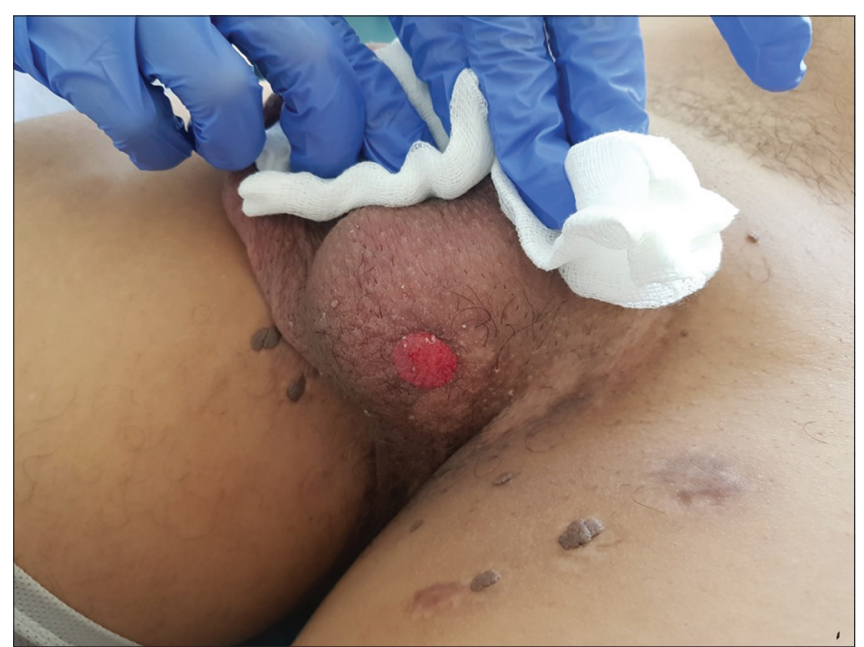

Figure 1: Well-limited lobulated, reddish exophytic vascular nodule, easily bleeding and measuring $4 \mathrm{~cm}$, on the posterior surface of the scrotum.

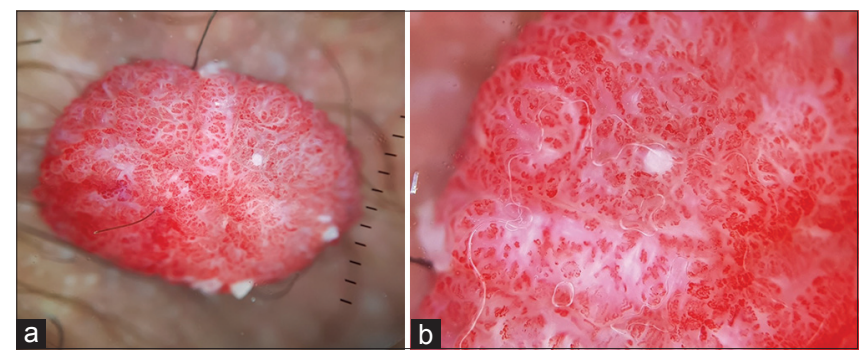

Figure 2: (a) Presence on dermoscopy of multiple reddish homogeneous area also named vascular lagoons separated by white rail lines corresponding to fibrous septas. (b) At higher magnification dermoscopy, we found a rich, linear, irregular and tortuous vascularization in these lagoons.

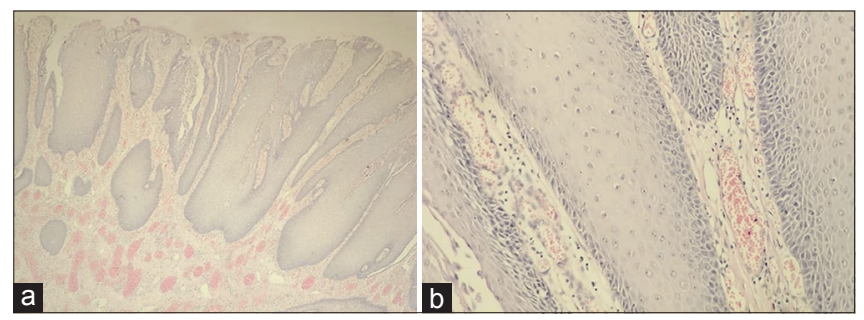

Figure 3: (a) Encapsulated, well-defined dermal based lobular vascular proliferation of small vessels, surrounded by mixed inflammatory infiltrate, surmounted by acanthosis and papillomatosis. (b) Presence of koilocytes related to the subjacent condyloma.

examinations revealed an encapsulated, well-defined dermal-based lobular vascular proliferation of small vessels, surrounded by mixed inflammatory infiltrate, surmounted by acanthosis and papillomatosis (Fig. 3a), with the presence of koilocytes related to the subjacent condyloma (Fig. 3b).

\section{DISCUSSION}

No hierarchy of first-line treatments for anogenital warts is provided in international guidelines. Ablative (c) Our Dermatol Online e.2021 techniques are commonly used by physicians to remove warts in daily practice. In our context, trichloroacetic acid is very often used, given the availability of the product and its low price. Physician-applied trichloroacetic acid (TCA; 30-90\%) treatment causes a chemical burn that destroys the AGW. This process requires a skilled professional to choose the appropriate lesion and duration of application but it is easy to apply and effective for treating AGW, with clearance rates of 70-100\% reported in clinical studies [2]. However, side-effects such as local discomfort, burning and ulceration are common, hence the need for careful application [3]. To the best of our knowledge, no case of pyogenic granuloma secondary to the application of TCA for the treatment of condyloma has been published in the literature. Pyogenic granuloma is a benign vascular proliferation of the skin. Hands, lower lips and gingiva are most frequently affected [1]. Genital localization is very rare, it is mainly the vulva in women [6] and the penis in men [7]. only one case of scrotal GP has been found in the literature [8]. Because malignant tumors, such as amelanotic melanoma, can be misdiagnosed as PG, histopathology is mandatory for the correct diagnosis, even though dermoscopy can play a primary role in the prompt recognition of PG, showing highly repetitive patterns that can support the diagnosis [9]. In particular, the presence of reddish homogeneous area, white rail lines (even more so when associated together) are strongly suggestive of $\mathrm{PG}$, on the other hand, with dermoscopy, it is not uncommon to detect ulceration and vascular structures that do not rule out malignancies [10]. Vascular structures are observed in $45 \%$ of cases, they can be linear-irregular or polymorphic and atypical [9]. Despite its benign nature, GP can have a significant negative impact on patients' quality of life, and therefore appropriate therapy is needed. Over the years, many therapeutic modalities have been used in order to successfully treat this condition. A successful combination therapy of timolol with trichloroacetic acid (TCA) has been described by Chiriac et al. Timolol, $0.1 \%$, was applied in occlusive dressings twice daily for 2 weeks, followed by one or two applications of $70 \%$ TCA, leading to complete resolution of PG's lesions in two pediatric patients [11].

\section{CONCLUSION}

Trichloroacetic acid is one of the most widely used therapeutic modalities in daily practice for the treatment of ano-genital condylomas. Moreover, we report for the first time a pyogenic scrotal granuloma as a side effect of this technique, with an unusual 
location in the scrotal region. It should also be noted that TCA has also been used as a treatment for pyogenic granuloma.

\section{REFERENCES}

1. Wollina U, Langner D, França K, Gianfaldoni S, Lotti T, Tchernev G. Pyogenic granuloma - a common benign vascular tumor with variable clinical presentation: new findings and treatment options. Open Access Maced J Med Sci. 2017;5:423-6.

2. O'Mahony C, Gomberg M, Skerlev M, Alraddadi A, de Las HerasAlonso ME, Majewski S, et al. Position statement for the diagnosis and management of anogenital warts. J Eur Acad Dermatol Venereol. 2019;33:1006-9.

3. Barton S, Wakefield V, O'Mahony C, Edwards S. Effectiveness of topical and ablative therapies in treatment of anogenital warts: a systematic review and network meta-analysis. BMJ Open. 2019;9:e027765.

4. Bhatia N, Lynde C, Vender R, Bourcier M. Understanding genital warts: epidemiology, pathogenesis, and burden of disease of human papillomavirus. J Cutan Med Surg. 2013;17 Suppl 2:S47-54.

5. Bertolotti A, Ferdynus C, Milpied B, Dupin N, Huiart L, Derancourt C. Local management of anogenital warts in non-immunocompromised adults: a network meta-analysis of randomized controlled trials. Dermatol Ther (Heidelb). 2020;10:249-62.

6. Abreu-Dos-Santos F, Câmara S, Reis F, Freitas T, Gaspar H, Cordeiro M. Vulvar lobular capillary hemangioma: a rare location for a frequent entity. Case Rep Obstet Gynecol. 2016;2016:3435270.

7. Katmeh RF, Johnson L, Kempley E, Kotecha S, Hamarneh W, Chitale S. Pyogenic granuloma of the penis: an uncommon lesion with unusual presentation. Curr Urol. 2017;9:216-8.

8. Abdul Gaffoor PM. Pyogenic granuloma of the scrotum. Cutis. 1998;62:282.

9. Zaballos P, Carulla M, Ozdemir F, Zalaudek I, Bañuls J, Llambrich A, et al. Dermoscopy of pyogenic granuloma: a morphological study. Br J Dermatol. 2010;163:1229-37.

10. Piccolo V, Russo T, Moscarella E, Brancaccio G, Alfano R, Argenziano G. Dermatoscopy of vascular lesions. Dermatologic Clinics. 2018;36:389-95.

11. Chiriac A, Birsan C, Podoleanu C, Moldovan C, Brzezinski P, Stolnicu S. Noninvasive treatment of pyogenic granulomas in young children with topical timolol and trichloroacetic acid. J Pediatr. 2016;169:322-322.e1.

Copyright by Aida Oulehri, et al. This is an open access article distributed under the terms of the Creative Commons Attribution License, which permits unrestricted use, distribution, and reproduction in any medium, provided the original author and source are credited.

Source of Support: Nil, Conflict of Interest: None declared. 